\title{
Is Equity on Their Mind? Documenting Teachers' Education Equity Mindset
}

\author{
Louis S. Nadelson ${ }^{1, *}$, Rachelle Miller ${ }^{1}$, Helen $\mathrm{Hu}^{1}$, Na Mi Bang ${ }^{1} \&$ Brandy Walthall ${ }^{1}$ \\ ${ }^{1}$ University of Central Arkansas, Conway AR 72035, USA \\ *Correspondence: University of Central Arkansas, Conway AR 72035, USA. Tel: 1-501-450-3254. E-mail: \\ lnadelson1@uca.edu
}

Received: August 26, 2019

Accepted: September 19, 2019 Online Published: October 17, 2019

doi:10.5430/wje.v9n5p26

URL: https://doi.org/10.5430/wje.v9n5p26

\begin{abstract}
An education equity mindset is fundamental to assuring all students are supported to achieve to their highest capacity. We have identified six attributes of an educational equity mindset critical to assuring teachers' practices and professional choices are aligned with meeting the needs of all students. In an effort to promote education equity mindset among teachers we determined there was a need to first empirically document the construct. We surveyed 452 teachers in the southern region of the United States. Our results indicate that we effectively measured our definition of education equity mindset. We found multiple differences in the mindset attributes based on personal and professional variables. Our data indicate that teachers may hold competing or fragmented mindsets. Our research uncovered multiple needed lines of research and implications for teacher preparation and professional development.
\end{abstract}

Keywords: equity, culturally responsive, leadership, teaching, success for all

\section{Introduction}

\subsection{Introduction to the Problem}

Public education is valued for providing opportunity for all to learn and achieve. Thus, there is an expectation that the educators and administrators working in public education are committed to ensuring all are educated. Yet, if we want all to achieve their highest potential, education for all cannot mean one-size-fits-all. To provide equitable education, teachers and administrators need to embrace practices associated with education equity. These practices include student-centered learning, culturally responsive teaching, inclusion, and other actions that provide students opportunity to learn based on what they know and the resources they need. For teachers to embrace the practices of educational equity they need to understand and internalize the beliefs that all can learn, grow, and engage. We argue that achievement of education equity requires teachers need to adopt and maintain education equity mindset.

Our research is focused on assessing public school teachers' education equity mindset. In our search of the literature we were able to find references to education equity, but we were not able to locate any reports that proposed a model of an education equity mindset and then gathered the data needed to empirically verify the model. The gap in the literature motivated us to ask what are the elements of an educational equity mindset, what are the profiles of teachers who hold an education equity mindset, and what are the practices of teachers who hold an education equity mindset?

\subsection{Educational Equity Mindset}

A mindset is a complex multi-faceted construct that can be conceived in multiple ways through different lenses (Armor \& Taylor, 2003; French, 2016; Gollwitzer \& Bayer, 1999). Through this review of different mindset conceptions French (2016) argues that mindset as a construct should be considered as being on a spectrum rather than as a specific concept. Embracing French's recommendation, we based our definition of mindset as being a combination of perceptions, attitudes, beliefs, thoughts, and dispositions, that are applied to guide professional (or personal) actions or choices. Thus, we perceive a mindset to be reflective of the identity of individuals, influencing how they interact with others, and how they perceive their role and responsibilities (Taylor \& Gollwitzer, 1995) that occur along a spectrum (French, 2016). 
Situating our conception of mindset within the perception of education equity, we created the education equity mindset. We argue that an education equity mindset involves beliefs, perceptions, behaviors, actions, and thoughts that promote and support equitable education. In part, we have adopted Jordan's (2010) definition of education equity to encompass the broader student population and associated factors such as ethnicity, social economic status, gender, disabilities, community, and resources. Thus, we consider an education equity mindset to be the knowledge, beliefs, and dispositions supportive of advocating and working toward equitable education for all learners. Such actions include culturally responsive teaching, personal responsibility for creating equity, inclusive teaching and learning, working to provide success for all, providing quality education, student-centered learning, informal leadership, and knowing and understanding your students.

We have also adopted French's (2016) perspective and placed the education equity mindset on a spectrum. In our model of an education equity mindset, we have created a spectrum that ranges from weak to strong expression of the mindset (see Figure 1). At the weak end of the spectrum, the mindset is aligned with being culturally neutral, teacher-centered learning, perceiving that students are totally responsible for their success, viewing leadership as a hierarchy, thinking that only some students will succeed, treating all students to same, and access is for the deserving. In contrast, at the strong end of the education equity mindset spectrum a teacher would be culturally responsive, engage in student-centered learning, take responsibility for student success, engage in informal leadership, perceive all students can succeed, know and understand student populations, and works to provide access to all. Thus, at the weak end, the mindset would be characterized by privilege, preference, and segregation, while the strong end of the spectrum would be characterized by inclusion, support for all, and advocacy for equity. We anticipate that because the mindset is on a spectrum that teachers may express elements at both the weak and strong end of the spectrum, and may shift their place on the spectrum based on context or conditions.

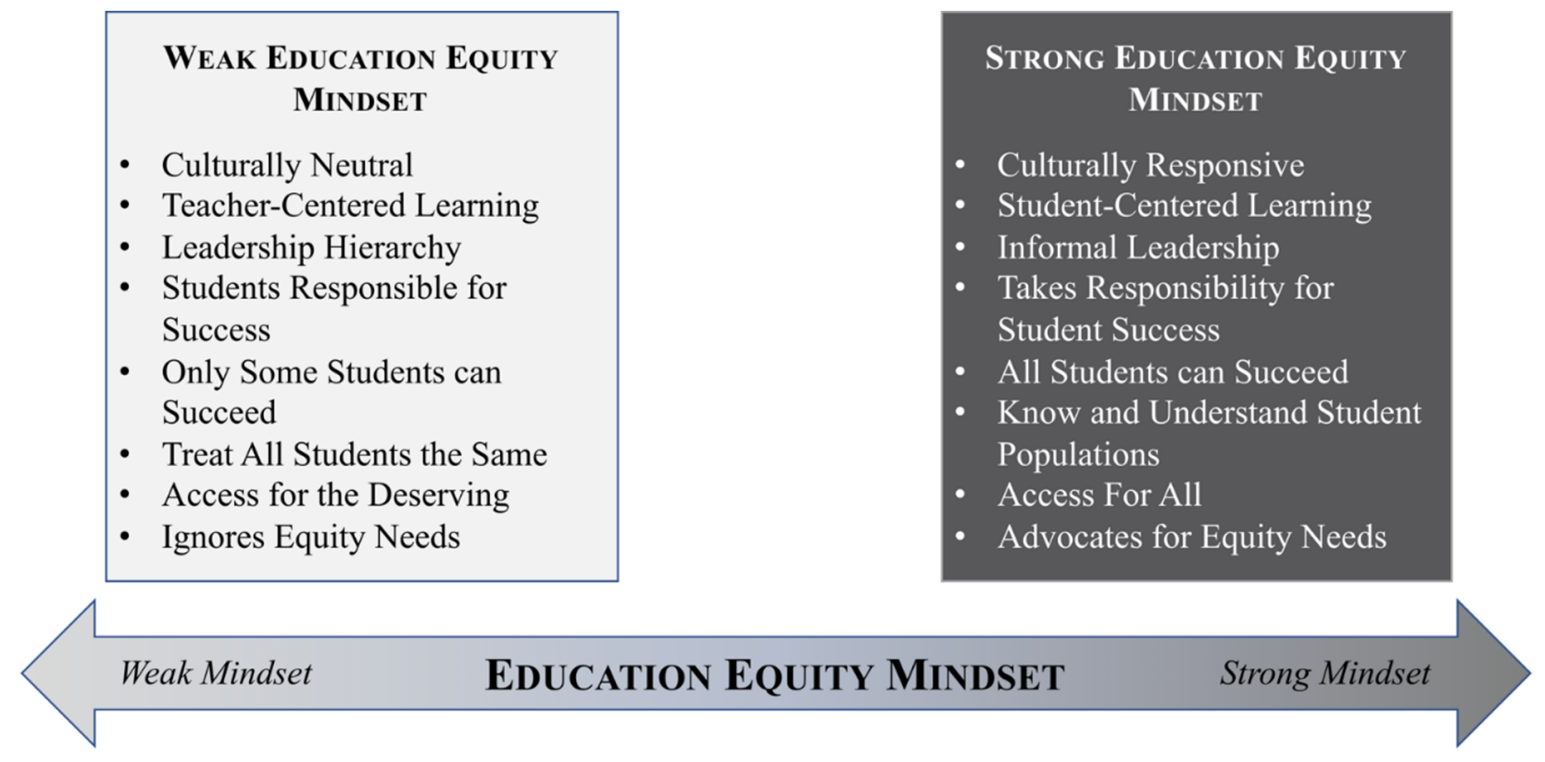

Figure 1. The Education Equity Mindset Spectrum

Teachers' beliefs, knowledge and dispositions are critical to social justice and supporting all students in achieving to their highest capacity. Thus, we maintain there is merit in creating and validating a model of an education equity mindset by assessing the extent to which teachers hold and express facets of equitable education.

\subsection{Culturally Responsive Teaching}

As classrooms are becoming more racially and ethnically diverse (U.S. Census Bureau, 2018), teachers need to understand the influence of cultural diversity on learning and respond by providing culturally responsive teaching. Culturally responsive teaching includes understanding and supporting the cultural characteristics, experiences, and perspectives of students (Gay, 2002). Culturally responsive teaching is based on the assumption that student achievement will increase when students' perspectives, cultures, and experiences are recognized and respected in the learning environment (Gay, 2002; Sleeter, 2012). 
There has been an increase in the amount of research on culturally responsive teaching in K-12 education and teacher education. Reports of research indicate that teachers need to learn how to implement a culturally responsive curriculum into the classroom and help students acknowledge and understand diverse topics and issues regarding poverty, social class, culture, ethnicity, and other relevant topics (Montgomery, 2001; Villegas \& Lucas, 2002). Gay (2002) argues culturally responsive teaching requires the development of a culturally diverse knowledge base and adoption of a culturally relevant curriculum in teaching. Rychly and Graves (2012) emphasize the teacher characteristics required for culturally responsive teaching including reflecting on their attitudes and beliefs about other cultures, examining their culture, and being knowledgeable about students' cultures. Thus, there is evidence to indicate that culturally responsive teaching is crucial to make learning more relevant and effective for all students.

There are a growing number of indicators and evidence which show that students from diverse backgrounds are underperforming and underachieving compared to mainstream students (Cartledge \& Kourea, 2008; Rychly \& Graves, 2012). A potential solution to the achievement gap, is in part, teacher engagement in culturally responsive teaching. Culturally responsive teaching is a necessary part of an education equity mindset because of the potential to support equal opportunity for learning. Given the need to enhance the learning for all students, there is justification for including culturally responsive teaching as a critical component of an education equity mindset.

\subsection{Responsibility for Creating Equity}

Teachers and other school personnel need to take responsibility for and work toward creating equity for all students. Taking responsibility may begin with the development of an understanding of the causes of equity gaps and the need to close those gaps. Equity-minded teachers understand their responsibility to examine practices and policies that contribute to or hinder an environment of equity (Kaur, 2012). While some teachers identify what others are doing to close equity gaps, perhaps a better route would be to take responsibility for identifying inequities and then attend to student needs on a case-by-case basis and address school-specific equity needs (Cochran-Smith, Shakman, Jong, Tarrell, Barnatt, \& McQuillian, 2009). Equity-minded teachers perceive it is their duty to use inquiry to identify equity issues and then examine current practices to devise a plan for addressing the identified inequities (Malcom-Piqueux \& Bensimon, 2017).

An equity mindset is important because it is believed that the mindset of a teacher can be transferred, influencing their students' mindset development (Haimovitz \& Dweck, 2017). We argue that for teachers to engage in addressing the inequities in education it is essential for teachers take the initiative to actively engage in developing their equity mindset. Given the importance of teachers taking responsibility for promoting education equity to assuring success for all, there is justification for considering responsibility for promoting education equity as a critical element of an education equity mindset.

\subsection{Success for All Learners}

Teachers and school leaders are essential for cultivating equitable school climates that can lead to the success of all students. Acquiring a mindset of education equity requires educators to be mindful about empowering those who may be considered powerless or marginalized in decision-making processes. When educators seek to create learning environments in which all can succeed the resulting education system is excellent and equitable (Harris, Carrington, \& Ainscow, 2018). To achieve success for all students, teaching would have to be adjusted to meet the needs of each student (Francia, 2013). The students' learning should be based on their backgrounds, knowledge, capacities, and experiences. To provide differentiated instruction for success for all, education systems have to be implemented to use curriculum in which the contents are adjusted to meet the students' needs, interests, and experiences (Francia, 2013). To further engage students, a curriculum created to assure all succeed allows students to be involved in what they study and how they will learn (Harris, Carrington, \& Ainscow, 2018).

High quality educators provide equitable opportunities for their students, regardless of school characteristics. Unfortunately, students in low-performing schools with diverse populations are less likely to taught by well qualified teachers (Center for Public Education, 2012) potentially resulting in poor student-educator relationships. For instance, Delpit (2012) discusses the negative mindset of some educators, “...we educators too often assume that there is something deficient in low-income children or their families that stunts learning. We fail to pay sufficient attention to what we can control - what does or doesn't happen in classrooms" (p. 56). Ensuring the success of all students requires strong collaborations between administration and teacher by creating positive school climates, promoting the use of culturally responsive teaching, providing opportunities for family engagement with diverse groups of parents, and cultivating equitable academic experiences for all students (Schalanger, 2018). Because of the importance of working toward the success for all to equitable education, we argue that success for all is an essential component of an education equity mindset. 


\subsection{Access to Quality Education}

Access to quality education is fundamental to education for all. Educators, parents, and politicians tend to agree that all students deserve access to quality education. However, achieving the goal of access for all is challenged by the complexity of defining and assessing quality education (Pianta, Downer, \& Hamre, 2016). Regardless of the specifics of the definition of quality education, there is wide agreement that education should prepare graduates for additional education or employment (Lee \& Walsh, 2016). The desire for quality education has led to many national initiatives such as the No Child Left Behind Act (United States Department of Education, 2002) which was reauthorized as Every Child Succeeds Act (United States Department of Education, 2015). The motivation behind these initiatives is the desire to provide quality of education to all in the United States.

It is important to maintain awareness of the role of the teacher when working to provide access to quality education. The current focus on high stakes testing associated with national initiatives and measures of teacher accountability can be detrimental to teachers taking an active role in promoting equity and access to quality education (Au, 2011). Teachers' perceptions of national initiatives may lead them to focus on testing and other metrics that may hinder their expression and embrace of an education equity mindset and the associated actions of assuring access to quality education for all students $(\mathrm{Au}, 2016)$. It is therefore important for teachers to be empowered and provided with the expectation that they are to ensure access to a quality education experience for everyone by helping students commit to continued growth and an eagerness to learn (Haimovitz \& Dweck, 2017). Given the importance of access to quality education to equitable education, there is warrant for including teacher promotion of quality education for all as part of an education equity mindset.

\subsection{Student-Centered Learning}

Student-centered instruction is defined by Brown (2008) as, "when the planning, teaching, and assessment revolve around the needs and abilities of the students. The teacher shares control of the classroom, and students are allowed to explore, experiment, and discover on their own..." (p. 30). Extending the definition, Granger and colleagues (2012) maintain that in student-centered instruction the teacher acts as a facilitator to support student learning. Further, student-centered learning can be designed to promote the development of higher-order thinking skills, critical thinking, and problem solving (Brush \& Saye, 2001). In addition, student-centered learning requires collaboration is an essential component to provide students with opportunities to discuss different viewpoints and perspectives, negotiate meanings, and delegate responsibilities to successfully solve problems. We argue that student-centered instructional strategies promote educational equity by providing opportunities for the consideration of individual social and developmental interests (Larrier, Hall, Linton, Bakerson, Larrier, \& Shirley, 2016).

Student-centered instruction has been effective for increasing equity in access to technology, equity in experience, equity in gender difference, and equity among diverse student populations (Bevan, Ryoo \& Shea, 2017; Brown, 2017; Buffum, Frankosky, Boyer, Wiebe, Mott, \& Lester, 2016). Student-centered learning increases education equity through the integrations of social or community relevant content and allowing students to choose learning activities and ways to demonstrate knowledge (Bevan, Ryoo, \& Shea, 2017; Severance, et al., 2016).

In student-centered instruction the students are often engaged in meaningful learning opportunities that draw upon personal experiences (e.g., Buffum, et al., 2016), in which students can ask questions, investigate answers to those questions, and develop knowledge and skills through activities (e.g., Severance et al., 2016). Because student-centered learning can be personalized, the instructional strategy increases opportunity for education equity. Kinloch (2015) contends that it is important for teachers to connect to students' out-of-school experiences and relate school curricula to students' community and culture to increase academic achievement and improve educational justice. Thus, we maintain that there is justification for exploring teachers' expression of student-centered instruction as part of their education equity mindset.

\subsection{Informal Leadership}

Teachers may be involved in formal leadership roles in their schools such as department chair or instructional coach. However, of interest to us is their engagement in informal leadership roles that are commensurate with those in distributed leadership models (Harris, 2008). Whitaker (1995) argues for the importance of teachers as informal leaders to foster school change and social justice. Teachers play an important role as informal leaders in catalyzing changes in school climate, initiatives, and goals (Brooks, Jean-Marie, Normore, \& Hodge, 2007; Danielson, 2007). More specifically, Patterson and Patterson (2004) claim that teacher leaders are those teachers who inspire others to join them in working toward improving teaching and learning. In our work, we consider a critical aspect of education 
equity mindset is informal leadership focused on enhancing teaching and the learning of all students, particularly those who are most disadvantaged.

Teachers become informal leaders when they do not hold a formal leadership role outside of the classroom but are recognized as being knowledgeable, insightful, and respected (Whitaker, 1995). These informal teacher leaders are usually recognized as being highly innovative, motivated, and engaged professionally, and would be difficult to replace (Patterson \& Patterson, 2004). Given the potential for transforming school culture and making a difference in teaching and the learning of all students, it is important to consider informal leadership as an element of an education equity mindset.

\subsection{Know and Understand Student Populations and Their Needs}

In order for teachers to establish rapport with students and effectively work with diverse student populations, it is crucial that teachers first recognize the views of students and their needs (Chamberlain, 2005; McAllister \& Irvine, 2000). To understand the needs of students, teachers should be able to listen carefully, be knowledgeable of child and adolescent development, and also support the growth of students in several domains which include cognitive, social, physical, and emotional aspects (Darling-Hammond, 2008). By understanding student populations and needs, teachers can be more culturally responsive in their teaching, develop meaningful student-centered learning opportunities, and enhance the success for all leading to higher levels of education equity.

Various studies have examined the importance of understanding students and their needs as an essential element for educational equity. Understanding students' needs provides teachers with the opportunity to know what questions to ask students, and also how to elicit student thinking, as well as help students articulate their ideas and better prepare students to perform their work (Grossman, Hammerness, \& McDonald, 2009). There is a need to more specifically understand student populations and support their needs; however, only a limited number of teachers feel that they are adequately prepared for teaching and working with diverse student populations (Boyd, Goldhaber, Lankford, \& Wyckoff, 2007; Lewis, Parsad, Carey, Bartfai, Farris, \& Smerdon, 1999). Although working with diverse student populations and understanding their needs are emphasized in teaching and teacher education, there is scant research about teachers' thoughts and reflection on this agenda in terms of educational equity. We have included understanding and knowing student populations in our education equity mindset model because student success and equitable education is enhanced when teachers can integrate content and curriculum aligned with their students' interests and needs.

\section{Method}

\subsection{Research Objectives}

Our overarching research objectives were to determine the elements of an educational equity mindset, the profiles of teachers who hold an education equity mindset, and the practices of teachers who hold an education equity mindset. To achieve these objectives, we developed the following guiding research questions:

- To what level do teachers express elements of an educational equity mindset?

- What is the relationship among the educational equity mindset elements expressed by teachers?

- What are the profiles of teachers in relationship to the education equity mindset?

- What elements of the education equity mindset do teachers express in their reflections on their practice?

\subsection{Participants}

We recruited our participants from a region in the southern United States. The 452 teachers who participated in our research and completed our survey were, on average, 44.28 years old $(\mathrm{SD}=11.19)$ and had taught for an average of 15.91 years $(S D=10.05)$. About $86 \%$ of the teachers identified as female, and $13 \%$ identified as male with $1 \%$ declining to answer or indicating "other" for their gender identity. The majority of the teachers were Caucasian (88\%) followed by a much smaller percent of African Americans (5\%), Native American (2\%), Asian (1\%), Hispanic (1\%), and identification of "Other" or "Mixed" (3\%). The majority of the participants held a master degree (57\%) or a bachelor degree (27\%), with 7\% holding an education specialist degree, $5 \%$ holding a post-graduate certificate, $3 \%$ holding a doctorate, and $1 \%$ indicating "other" for their highest degree. The participants were fairly equally split among urban (33\%), suburban (30\%), and rural (37\%) communities. The participants were also fairly equally split in their teaching in elementary school (26\%), middle/junior high schools (26\%), and high school (36\%), with $1 \%$ teaching preschool, $4 \%$ teaching in grades $6-12$ schools, $4 \%$ teaching in grades $\mathrm{k}-12$ schools, and $3 \%$ indicating 
"other" for their school type. About $63 \%$ of the teachers indicated that at least $50 \%$ of their students in their schools qualified for free and reduced lunch, $2 \%$ indicated less than $10 \%$ of the students in their schools qualified for free and reduced lunch, $24 \%$ indicated that between $10 \%$ and $50 \%$ of the students in their school qualified for free and reduced lunch, and $11 \%$ of the participants indicated that they did not know the percent of students in their school that qualified for free and reduced lunch.

\subsection{Survey Development}

To conduct our research, we needed an instrument that focused on teacher perceptions and practices associated with supporting equity in education, in particular a measure of our model of an education equity mindset. While there is some research on teacher engagement in education equity, there is a lack of a research tool designed to measure teachers' education equity mindset. The lack of research tools led us to develop a survey to assess K-12 teachers' perceptions and practices for engaging in and supporting education equity - a measure of their education equity mindset.

Given our interest in K-12 teachers, we contextualized our instrument to reflect common interactions and practices in K-12 schools. We began our instrument development with identifying the attributes or facets of education equity. As a team we discussed the potential issues, influences, processes, expectations, and limitations. Our discussion included perceptions of the importance of education equity for student learning and long-term success. Through our discussion we developed six critical facets of an educational equity mindset (see Table 1). We then shared our list with multiple education experts (researching and teaching in colleges of education) and asked them to rank the relevance of the attributes to a mindset of education equity. We had seven experts respond, and all strongly agreed that our attributes were essential to an educational equity mindset. We also asked them to include any additional attributes they thought were not represented in our list, but there were no additions.

Once we validated our set of attributes, we developed a series of Likert scale (or Likert-like scale) selected response items focused on teacher engagement or perceptions of one of the facets of an educational equity mindset. Through our item development process, we also developed a free response item asking teachers to share why they became a teacher and another item asking them the greatest challenges they have in working with diverse student populations. Following our initial item development, we aligned the items with our study focus to assure we had a reasonable number of items to address each of our guiding research questions and assess the facets of an education equity mindset. Through the alignment process, we eliminated some items, added a few more and modified some resulting in at least two items for each of the six education equity mindset attributes. Following our survey development, we validated the items through sharing our survey with additional educational experts and asked for their feedback. We considered the feedback from the five experts that responded and made minor edits resulting in the final form of our survey.

Our final survey contained several demographic items, two free response items, and 23 selected response items. Our selected response items included statements such as, "It is my responsibility to teach my students to be respectful of others" and "I cannot expect high standards of performance from all of my students." which the participants responded to on a five-point Likert scale. We calculated the reliability to a Cronbach's alpha of .74, indicating an acceptable level of internal consistency.

\subsection{Data Collection}

Our data collection took place online. We invited teachers to complete our survey through the distribution of an email to numerous list-servs and to other educators who had access to group mailing lists such as school district superintendents. The email contained a brief description of our research and a link to our online survey. Our data collection took place over a three-week period.

\subsection{Analysis}

\subsubsection{Quantitative Data}

We began the analysis of our quantitative responses by conditioning our data which included removing responses that were not at least $90 \%$ complete. We then used the replace missing values feature in SPSS to insert the series mean for the skipped items in our data set. Once our data set was complete were aligned our quantitative items to our facets of an education equity mindset. We calculated the composite scores for the item groups representative of the different education equity attributes in preparation for our analysis. 


\subsubsection{Qualitative Data}

For our qualitative data, we began by creating a list of codes representative of each of our education equity mindset attributes (see Table 1). We developed the codes based on the literature, discussion, and perceptions of teachers. Our codes includes both positively and negatively phrased items.

Table 1. Attribute of an Educational Equity Mindset and Representative Codes

\begin{tabular}{ll}
\hline Education Equity Mindset Attribute & \multicolumn{1}{c}{ Representative Codes } \\
\hline $\begin{array}{l}\text { Responsibility for Promoting } \\
\text { Equity (RPE) }\end{array}$ & $\begin{array}{l}\text { Supporting all students, differentiating based on needs, treating all } \\
\text { students the same, differentiated instruction }\end{array}$ \\
Success for All (SFA) & $\begin{array}{l}\text { All students will succeed, high expectations for all, equal opportunity } \\
\text { to engage for special needs students }\end{array}$ \\
Knowing and Understanding & Recognition of different populations, influence of family and peers, \\
Student Population Needs (KUSP) & $\begin{array}{l}\text { absences, know culture, difficulty in relating } \\
\text { Culturally Responsive Teaching }\end{array}$ \\
(CRT) & $\begin{array}{l}\text { Stereotyping, communication, responding in culturally appropriate } \\
\text { ways, same expectations for all }\end{array}$ \\
Student-Centered Learning (SCL) & $\begin{array}{l}\text { Student choice, project based, student teams, community-based } \\
\text { lessons, teach control, lecture, curriculum }\end{array}$ \\
Informal Leadership (IL) & Responsibility, lack of efficacy, lack of engagement, leadership \\
\hline
\end{tabular}

\subsubsection{Data Coding}

We began our coding process as a group with all team members contributing to the discussion of coding the first 20 qualitative responses. Following the group experience a pair of team members were assigned to independently code the same set of items. We formed three pairs of researchers and each of us in the pairs independently coded the same subset of the data set. Once the independent coding was complete, the pairs of coders met and discussed their results, and through discussion they came to consensus in their designation of the attributes to the responses.

\section{Results}

\subsection{Expression of Education Equity Mindset Attributes}

Our first guiding research question asked, To what level do teachers express attributes of an educational equity mindset? To answer this item, we examined the coding of the teachers' responses to our free response items that would reflect the attributes that are on the minds of the teachers. Our analysis revealed, substantial differences in the attributes that the teachers emphasized in their responses. In the item asking them to share why they teach, the majority of the participants focused on success for all followed by informal leadership (see Figure 2). The participants shared some instances for student-centered learning. However, less frequently communicated by the participants was knowing and understanding student populations, responsibility for promoting equity, and culturally responsive teaching. It is worth noting the relatively low number of responses that reflected a commitment to promoting educational equity.

In contrast, when asked to share their biggest perceived challenges in working with diverse populations, the participants tended to focus on knowing and understanding student populations and on culturally responsive teaching. There is a notable decline in the focus on success for all and in the focus on informal leadership. The responses of the participants included more responses that reflected a responsibility for promoting educational equity, but remained relatively low. Our results reflect a shifting in the communication of education equity mindset attributes based on the context or the conditions in which teachers think about their role and professional responsibilities. 


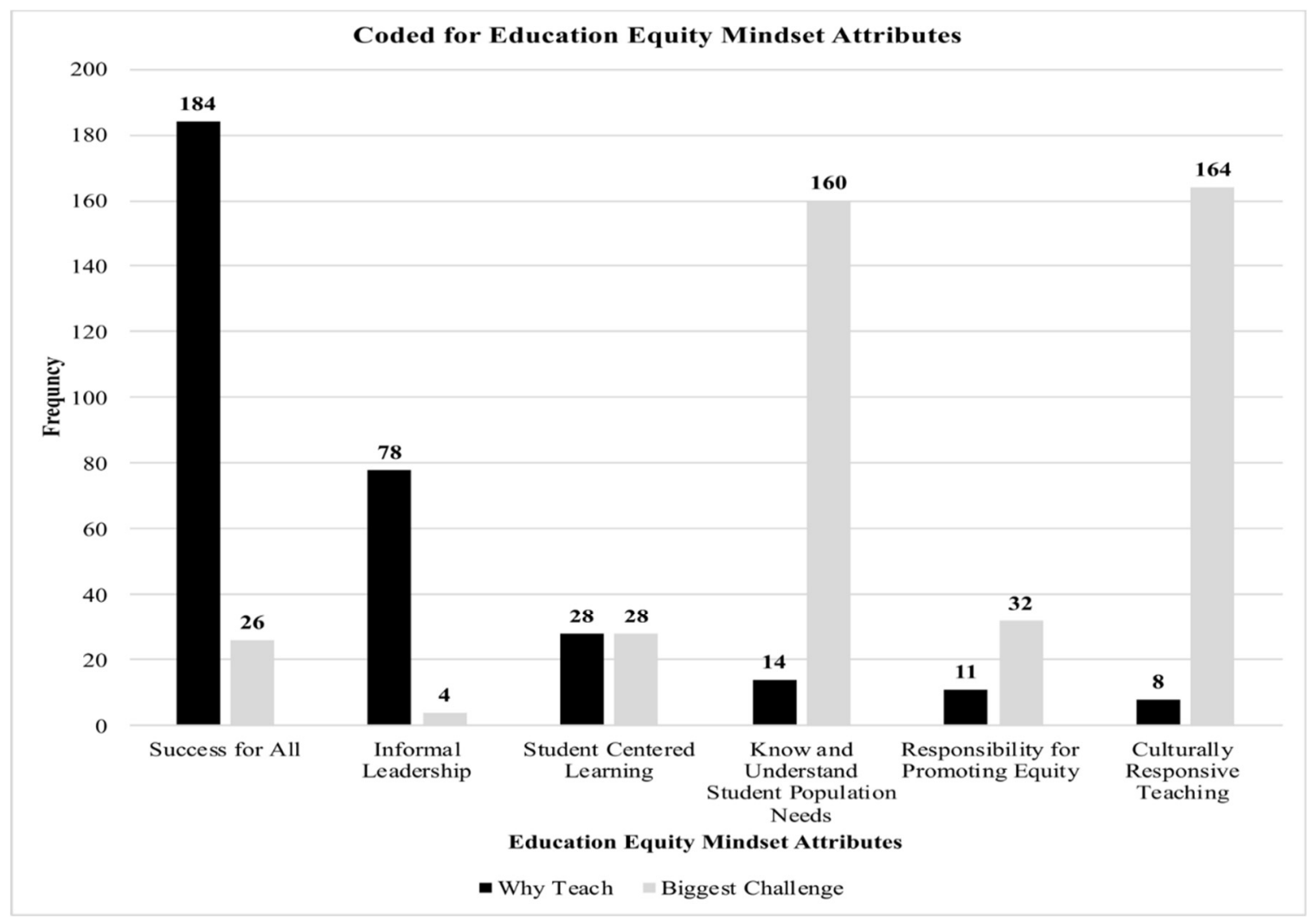

Figure 2. The Frequency of the Coded Themes in the Two Free Response Items

In addition to the shift in the focus on education equity mindset attributes, we also found a shift in the expression of the attributes with a shift in context. For example, in the communication of success for all in the response to "why I teach" the participants include adoration of students, making a difference, and showing students they can be successful. In contrast, the communication of success for all in the responses to the "greatest challenges with working with diverse populations" the focus is on motivating the student to try hard and value what is being taught (see Table 2). We noted a consistent shift from self and teacher ownership of responsibility or conditions in the responses to "why I teach" toward student responsibility or ownership of conditions when responding to the "greatest challenges with working with diverse populations." We interpret the shift as a potential conditional expression of attributes of an educational equity mindset and as being potentially reflective of a shift in the teachers' perceptions of their sphere of influence.

Table 2. Expression of Education Equity Mindset Attributes in Two Different Contexts

\begin{tabular}{lll}
\hline Attribute & Representative Answer to - "Why I teach:" & $\begin{array}{l}\text { Representative Answer to - "Greatest } \\
\text { Challenges you face working with diverse } \\
\text { groups" }\end{array}$ \\
\hline $\begin{array}{l}\text { Success for All } \\
\text { (SFA) }\end{array}$ & $\begin{array}{l}\text { I love working with children, wanted to make a } \\
\text { difference in the lives of low-income children by hard in class and value what I am trying to } \\
\text { showing them they can be successful, and teach them } \\
\text { someone does care about them }\end{array}$ \\
$\begin{array}{l}\text { Student-Centered } \\
\text { Learning (SCL) }\end{array}$ & $\begin{array}{l}\text { I really like seeing the links made between Giving them choices between texts that will } \\
\text { learning and their interests and being able to help meet an assignments instructional and } \\
\text { nurture those links and show them where and how curriculum need will help them buy into the } \\
\text { computer programming can be relevant to lesson and be committed to seeing it } \\
\text { whatever field of study or profession they choose. }\end{array}$ \\
& $\begin{array}{l}\text { through. It's about modeling respect for } \\
\text { basic human values and proper social } \\
\text { interactions. It's about teaching them to }\end{array}$ \\
\hline
\end{tabular}




\begin{tabular}{|c|c|c|}
\hline & & $\begin{array}{l}\text { think and to think for themselves and to ask } \\
\text { "Why?" Why are you asking certain } \\
\text { questions within certain words? Why is } \\
\text { someone trying to get me to think about a } \\
\text { certain topic in a certain way. Like the } \\
\text { various questions in this survey. }\end{array}$ \\
\hline $\begin{array}{l}\text { Know and } \\
\text { Understand Student } \\
\text { Population Needs } \\
\text { (KUSP) }\end{array}$ & $\begin{array}{l}\text { I work in the Title I program and I want to help } \\
\text { children become sufficient readers so they can } \\
\text { support themselves and their families. I also want } \\
\text { them to be able to read to their children. }\end{array}$ & $\begin{array}{l}\text { Learning about their backgrounds in a } \\
\text { non-obtrusive way. No middle school kid } \\
\text { wants to be singled out. }\end{array}$ \\
\hline $\begin{array}{l}\text { Culturally } \\
\text { Responsive } \\
\text { Teaching (CRT) }\end{array}$ & $\begin{array}{l}\text { I teach so that I can provide better opportunities to } \\
\text { kids who grew up very poor like me. There are } \\
\text { several lower class children who could do so } \\
\text { much more with their lives and I want to be that } \\
\text { role model and show them how. I do that through } \\
\text { my coaching and teaching every day. Everything I } \\
\text { do revolves around this idea. }\end{array}$ & $\begin{array}{l}\text { Students that use their diversity as a } \\
\text { weapon. Comments such as, "It's because I } \\
\text { am black..." } \\
\text { (NOTE: Coded as a negative response) }\end{array}$ \\
\hline $\begin{array}{l}\text { Responsibility for } \\
\text { Promoting Equity } \\
\text { (RPE) }\end{array}$ & $\begin{array}{l}\text { Student opportunity is nowhere equitable in this } \\
\text { country and quality education that is accessible to } \\
\text { all students is the best way to create opportunity } \\
\text { in the lives of students. It is my goal as a teacher } \\
\text { to break gender and racial stereotypes and guide } \\
\text { students to dream beyond their vision. Ultimately, } \\
\text { I see my role as an educator of dire importance to } \\
\text { the national security of our country and the } \\
\text { perseverance of democracy. }\end{array}$ & $\begin{array}{l}\text { We have a very homogeneous population, } \\
\text { so it is hard to make sure that my students } \\
\text { empathize with diverse perspectives } \\
\text { without fetishizing other cultures. }\end{array}$ \\
\hline $\begin{array}{l}\text { Informal } \\
\text { Leadership (IL) }\end{array}$ & $\begin{array}{l}\text { Being around young people makes me feel } \\
\text { valuable and relevant; being a mentor, role model, } \\
\text { and teacher fulfills my wish to pay it forward. }\end{array}$ & Being able to have others get on board \\
\hline
\end{tabular}

\subsection{Relationship among Education Equity Mindset Attributes}

Our second guiding research question asked, what is the relationship among the educational equity mindset attributes expressed by teachers? To answer this item, we conducted a correlation analysis among the composite scores for each of our education equity mindset attributes. Our analysis revealed, all of our education equity mindset attribute subscale means were significantly correlated with the exception of success for all (SFA) and knowing and understanding student populations (KUSP) (see Table 3). The knowing and understanding student populations (KUSP) attribute subscale was correlated with informal leadership (IL) at the $p<.05$ level, but all other correlations were at the $p<.01$ level. Our results provide support for our expectation that teachers are likely to be consistent in their communication and expression of the attributes of education equity which provides evidence for an associated mindset.

Table 3. Correlations among Education Equity Mindset Attributes

\begin{tabular}{|c|c|c|c|c|c|}
\hline & SFA & SCL & IL & RPE & CRT \\
\hline KUSP & .06 & $.13^{* *}$ & $.12 *$ & $.15^{* *}$ & $.15^{* *}$ \\
\hline SFA & & $.39 * *$ & $.30 * *$ & $.28 * *$ & $.21 * *$ \\
\hline SCL & & & $.39 * *$ & $.31 * *$ & $.22 * *$ \\
\hline IL & & & & $.22 * *$ & $.28 * *$ \\
\hline RPE & & & & & $.23 * *$ \\
\hline
\end{tabular}




\subsection{Individual Differences and Education Equity Mindset}

Our third guiding research question asked, what is the relationship among individual differences of teachers in relationship to the education equity mindset? To answer this question, we examined the education equity mindset composite scores between and among participants based on their demographics and their school and community profiles. Our analysis revealed, female teachers $(N=387, M=3.91, S D=.60)$ expressed higher levels of student-centered learning, $(t(445)=2.81, p<.05)$ than male teachers $(N=60, M=3.67, S D=.65)$. We also found that female teachers $(N=387, M=3.84, S D=.32)$ had higher levels of the overall education equity mindset $(t(445)$ $=3.05, p<.01)$ than male teachers $(N=60, M=3.70, S D=.32)$. We found an inverse correlation between age and knowing and understanding student populations $(r=-.158, p<.01)$ such that as age increases levels of knowing and understanding student populations decrease. Our analysis revealed a positive correlation between age (as well as years of experience) and informal leadership, $(r=.10, p=.035)$, such that as are increases so do the levels of informal leadership. We found a positive relationship between years of teaching experience and levels of student-centered learning $(r=.11, p=.017)$ such that as years of experience increases so do levels of studentcentered learning. We found ethnicity to be a factor for differences in scores in levels of success for all $(F(6,445)=$ $3.13, p<.01)$ with Tukey post-hoc revealing teachers who identify as Native American scoring significantly higher than teachers who identify as Asian.

We found highest degree achieve to be predictive of multiple differences in the attributes of education equity. We found a significant difference in student-centered learning $(F(5,444)=2.40, p=.037)$, with the Tukey post-hoc revealing teachers with masters level degrees scoring significantly higher than teachers holding a bachelor degree. We found a difference in levels of the informal leadership scores $(F(5,444)=2.85, p=.015)$ with the Tukey post-hoc again revealing the teachers with master level degrees scored significantly higher than teachers holding a bachelor degree. Our analysis revealed differences in levels of culturally responsive teaching $(\underline{F}(5,444)=2.84, p=.015)$ with the Tukey post-hoc revealing teachers with education specialists degrees scoring significantly higher than teachers with bachelor degree.

Using community type as the factor we found significant differences in student-centered learning $(F(2,446)=5.12, p$ $<.01)$ with the Tukey post-hoc revealing urban teachers scoring significantly higher than suburban teachers. We also found differences in scores in informal leadership $(F(2,446)=3.28, p=.038)$ with Tukey post-hoc revealing urban teachers again scoring significantly higher than rural teachers.

The level of the school in which our participants' taught was found to be associated with differences in scores for the success for all attributes $(F(6,443)=4.43, p<.01)$ with Tukey post-hoc revealing elementary teachers scoring significantly higher than high school teachers. School level was also a factor for differences in the level of student-centered learning $(F(6,443)=6.08, p<.01)$ with Tukey post-hoc revealing elementary teachers scoring significantly higher than both middle/junior high school teachers and high school teachers. The level of the school of the teachers was also found to be a factor for differences in informal leadership $(F(6,443)=2.80, p<.01)$ with Tukey post-hoc revealing elementary teachers scored significantly higher than high school teachers.

We found no differences in the mindset attribute levels of the teachers based on levels of students eligible for free and reduced lunch in their schools, which suggests that the social economic status of the students is not a factor related to the expression of the attributes of an education equity mindset.

\subsection{Practice and Educational Equity Mindset}

Our fourth guiding research question asked, What elements of the education equity mindset do teachers express in their reflections on their practice and are they consistent? To answer this question, we compared the responses to our items which asked the teachers to share their biggest challenges in teaching diverse groups of students and why they teach (see Table 4). Our analysis revealed the teachers tended to focus on different education equity attributes depending on the context of teaching that they are considering. For example, when Participant 10 responded to "why I teach" the focus was on increasing the motivation of the students which is reflective of success for all, student-centered learning, and knowing and understanding student populations. However, the response by Participant 10 to what is the greatest challenge with working with diverse populations the focus shifted to getting the students to relate to each other which is reflective of knowing and understanding student populations and responsibility for promoting equity. Again, the data make it is apparent that the participants tend to shift their focus from why they teach when discussing their biggest challenge in working with diverse populations which suggests that their education equity mindset may be situational or aligned with a world view inconsistent with social justice. 
Table 4. Representative Responses to Two Different Free Response Items from the Same Participant

\begin{tabular}{|c|c|c|}
\hline Participant ID & Response to Why I teach & Response to Greatest challenge \\
\hline 10 & $\begin{array}{l}\text { I teach so I can show kids that "they } \\
\text { can" when they think "they can't". } \\
\text { [SFA, KUSP, SCL] }\end{array}$ & $\begin{array}{l}\text { Trying to get students to relate to one another in a society } \\
\text { where there is a division of SES and beliefs. [KUSP, } \\
\text { RPE] }\end{array}$ \\
\hline 162 & $\begin{array}{l}\text { I began teaching to make a difference, } \\
\text { but that is too broad. I now teach } \\
\text { because students need stability, } \\
\text { acceptance, and motivation. [SFA] }\end{array}$ & $\begin{array}{l}\text { The greatest challenge is working with students of low } \\
\text { socioeconomic backgrounds, parents who don't value } \\
\text { education, and students who know where the quickest } \\
\text { and most money can be made (illegally of course). The } \\
\text { combination of the three is difficult to overcome. } \\
\text { [KUSP] }\end{array}$ \\
\hline 191 & $\begin{array}{l}\text { I had teachers that made a real impact } \\
\text { on my life, and I wish to do the same. } \\
\text { It is also the perfect outlet for my } \\
\text { creativity and passion for my content. } \\
\text { [IL] }\end{array}$ & Gaining their trust and building rapport. [SFA] \\
\hline 301 & $\begin{array}{l}\text { I teach so that I can provide better } \\
\text { opportunities to kids who grew up very } \\
\text { poor like me. There are several lower } \\
\text { class children who could do so much } \\
\text { more with their lives and I want to be } \\
\text { that role model and show them how. I } \\
\text { do that through my coaching and } \\
\text { teaching every day. Everything I do } \\
\text { revolves around this idea. [CRT, SFA] }\end{array}$ & $\begin{array}{l}\text { My greatest battle is with the parents. Most of the parents } \\
\text { in my school do not care about it and sometimes have } \\
\text { nothing to do with their child's education. Most do not } \\
\text { care enough to even check grades during the interim or } \\
\text { the end of every } 9 \text { weeks. [KUSP] }\end{array}$ \\
\hline 345 & $\begin{array}{l}\text { I teach to give back to my community. } \\
\text { I like the hours, and I enjoy the } \\
\text { student's diversity. They teach me as } \\
\text { much if not more then I teach them. I } \\
\text { love making connections with my } \\
\text { student's parents and being part of the } \\
\text { growth of my students. [IL, CRT, } \\
\text { KUSP] }\end{array}$ & $\begin{array}{l}\text { Not understanding their living arrangements or their lack } \\
\text { of love at home. I struggle because I'm a mom of two } \\
\text { and it puzzles me that parents do not get involved with } \\
\text { their children. [KUSP] }\end{array}$ \\
\hline
\end{tabular}

\section{Discussion and Implications}

The goal of our research was to develop a foundation for measuring and documenting an education equity mindset of teachers. Based on the literature and expert input we developed a set of attributes thought to be associated with an education equity mindset. Our data collection provided us with empirical support for the mindset. There are multiple points of discussion and implications for our results.

\subsection{Expression of Education Equity Mindset Attributes}

Our finding that teachers will express attributes of an education equity mindset when promoted with unrelated questions, such as why do you teach, indicates that the attributes are included in the way they thinking about teaching and learning. However, it is also apparent from the participants' responses that they are not consistent in their expression of the mindset attributes. The shifting responsibility from themselves to the students in their responses to the challenges faced when working with diverse groups, reflects the potential for other mindsets that are independent of education equity. The inconsistent expression of an education equity mindset may result in fragmented commitment to supporting all students in their efforts to attain their highest level of achievement. Exploring other mindsets that teachers hold that may be independent and in competition with an education equity mindset is a needed direction for research. 


\subsection{Relationship among Education Equity Mindset Attributes}

Our finding that the attribute subscales were nearly all significantly (but not overly) correlated suggests that our scale is likely effective at measuring our definition of an education equity mindset. The correlations also indicate if the teachers are thinking a certain way, aligned or not aligned with an education equity mindset, they are consistent in their perceptions and practices associated with our mindset attributes. The implication for the correlation among the attributes is they may influence each other, such that professional development focused on one of the mindset attributes may influence the development of other mindset attributes. A protentional fruitful line of research is an exploration of how preparation or professional development aligned with one education equity mindset attribute may influence other education equity attributes and the mindset as a whole.

\subsection{Individual Differences and Education Equity Mindset}

We found a number of personal and professional variables that were associated with differences in the attributes of an educational equity mindset. We speculate that experience, grade level, school location, and the other variables are likely to foster or influence the development of education equity mindset attributes. It may also be that teachers choose to work in situations or conditions that are aligned with their worldview, which may or may not be consistent with an education equity mindset. For example, elementary school teachers are more likely to be female and are more likely to be focused on student wellbeing that teachers in upper grades, who are also more likely to be male and focused on curriculum content. The implication for our finding is that there may be certain groups of teachers that are in greater need of continuing education to support their development and expression of an education equity mindset.

\subsection{Practice and Educational Equity Mindset}

We found that teachers frame their practice in terms of working with students from diverse backgrounds differently than when they share why they teach. We speculate that teachers perceive the role of a teacher differently than their work as a teacher. The data suggest that teachers perceive the role of a teacher somewhat idealistically, as one who motivates and makes a difference, but perceive the work of a teacher as being more technical and procedural. The compartmentalization of perceptions of teaching as a profession and of the professional activities of teachers suggests what teachers want to do (or perceive teachers are supposed to do) and what they have to do may not be aligned. The misalignment is likely to lead to differences in perceptions and practices associated with an educational equity mindset. To bring alignment between the mindset associated with teaching as a profession and the professional activities of teachers may require a culture shift in which education equity is a priority and supported as a mindset among teachers to foster learning and success for all students.

\section{Limitations}

One limitation of our study was the methods we used for our data collection limited our capacity to gain additional details from the participants to develop deeper understanding of their responses. However, our collection of both quantitative and qualitative responses allowed for us to develop a baseline for establishing a teacher education equity mindset. In our future research we plan to conduct interviews and observations to gather data that allow for greater understanding of teacher holding and expression of an education equity mindset.

A second limitation of our research is that our data collection took place in a region within the southern United States. It may be possible that teachers in different regions or from different cultures may hold different perceptions and have different practices. Future research should focus on exploring the education equity mindset of teachers from different regions and cultures.

A third limitation of our research is the possibility that our model of an education equity mindset is incomplete. While we built our mindset model on the literature and validated with education research experts, we may have not included other attributes associated with an education equity mindset. Further research on teacher education equity mindset is needed to further validate our model.

A fourth limitation of our study is the individual difference variables we gathered and used for analysis. There may be addition personal and professional variables that are predictive of an education equity mindset that we did not consider or collect. The exploration of additional personal and profession variables in relation to predicting an education equity mindset is an excellent direction for future research. 


\section{Conclusion}

We engaged in our research project exploring teacher education equity mindset because of our conviction that all students should be supported to achieve to their highest capacity. We maintain that an education equity mindset is critical to continually remaining focused and providing the support needed for student success. We found a number of issues of fragmented mindsets or a disconnection between the application of the mindset of perceptions of practice and of the professional position. We are encouraged that our data suggests that we seem to have measured the construct that we have defined as an education equity mindset. We have exposed multiple conditions and relationships that need to be explored fully to understand the application and development of teachers' education equity mindset. We hope others will join us in continued exploration of the teacher education equity mindset.

\section{References}

Armor, D. A., \& Taylor, S. E. (2003). The effects of mindset on behavior: Self-regulation in deliberative and implemental frames of mind. Personality and Social Psychology Bulletin, 29(1), 86-95. https://doi.org/10.1177/0146167202238374

$\mathrm{Au}, \mathrm{W}$. (2011). Teaching under the new Taylorism: High - stakes testing and the standardization of the 21st century curriculum. Journal of Curriculum Studies, 43(1), 25-45. https://doi.org/10.1080/00220272.2010.521261

$\mathrm{Au}, \mathrm{W}$. (2016). Meritocracy 2.0: High-stakes, standardized testing as a racial project of neoliberal multiculturalism. Educational Policy, 30(1), 39-62. https://doi.org/10.1177/0895904815614916

Bevan, B., Ryoo, J., \& Shea, M. (2017). What if? Building creative cultures for STEM making and learning challenge students. Afterschool Matter, 25, 1-8.

Boyd, D., Goldhaber, D., Lankford, H., \& Wyckoff, J. (2007). The effect of certification and preparation on teacher quality. The Future of Children, 17(1), 45-68. https://doi.org/10.1353/foc.2007.0000

Brooks, J. S., Jean-Marie, G., Normore, A. H., \& Hodgins, D. W. (2007). Distributed leadership for social justice: Exploring how influence and equity are stretched over an urban high school. Journal of School Leadership, 17(4), 378-408. https://doi.org/10.1177/105268460701700402

Brown, J. C. (2017). A metasynthesis of the complementarity of culturally responsive and inquiry-based science education in K-12 settings: Implications for advancing equitable science teaching and learning. Journal of Research in Science Teaching, 54(9), 1143-1173. https://doi.org/10.1002/tea.21401

Brown, J. K. (2008). Student-centered instruction: Involving students in their own education. Music Educators Journal, 94(5), 30-35. https://doi.org/10.1177/00274321080940050108

Brush, T., \& Saye, J. (2001). The use of embedded scaffolds with hypermedia-supported student-centered learning. Journal of Educational Multimedia and Hypermedia, 10(4), 333-356.

Buffum, P. S., Frankosky, M., Boyer, K. E., Wiebe, E. N., Mott, B. W., \& Lester, J. C. (2016). Collaboration and gender equity in game-based learning for middle school computer science. Computing in Science \& Engineering, 18(2), 18-28. https://doi.org/10.1109/MCSE.2016.37

Cartledge, G., \& Kourea, L. (2008). Culturally responsive classrooms for culturally diverse students with and at risk for disabilities. Exceptional Children, 74(3), 351-371. https://doi.org/10.1177/001440290807400305

Center for Public Education. (2012). The United States of education: The changing demographics of the United States and their schools. Retrieved from http://www.centerforpubliceducation.org/research/changing-demographics-glance

Chamberlain, S. P. (2005). Recognizing and responding to cultural differences in the education of culturally and linguistically diverse learners. Intervention in School and Clinic, 40(4), 195-211. https://doi.org/10.1177/10534512050400040101

Cochran-Smith, M., Shakman, K., Jong, C., Terrell, D. G., Barnatt, J., \& McQuillan, P. (2009). Good and just teaching: The case for social justice in teacher education. American Journal of Education, 115(3), 347-377. https://doi.org/10.1086/597493

Danielson, C. (2007). The many faces of leadership. Educational Leadership, 65(1), 14-19. https://doi.org/10.1002/lia.4070190105

Darling-Hammond, L. (2008). Teacher learning that supports student learning. Teaching for Intelligence, 2(1), 
91-100.

Delpit, L. D. (2012). "Multiplication is for white people": Raising expectations for other people's children. New York, NY: The New Press.

Francia, G. (2013). The impacts of individualization on equity educational policies. Journal of New Approaches in Educational Research, 2(1), 17-22. https://doi.org/10.7821/naer.2.1.17-22

French II, R. P. (2016). The fuzziness of mindsets: Divergent conceptualizations and characterizations of mindset theory and praxis. International Journal of Organizational Analysis, 24(4), 673-691. https://doi.org/10.1108/IJOA-09-2014-0797

Gay, G. (2002). Preparing for culturally responsive teaching. Journal of Teacher Education, 53(2), 106-116. https://doi.org/10.1177/0022487102053002003

Gollwitzer, P. M., \& Bayer, U. (1999). Deliberative versus implemental mindsets in the control of action. In S. Chaiker (Ed.), Dual-process theories in social psychology, (403-422). New York, NY: Guilford Press

Granger, E. M., Bevis, T. H., Saka, Y., Southerland, S. A., Sampson, V., \& Tate, R. L. (2012). The efficacy of student-centered instruction in supporting science learning, Science, 338(6103), 105-108. https://doi.org/10.1126/science.1223709

Grossman, P., Hammerness, K., \& McDonald, M. (2009). Redefining teaching, re - imagining teacher education. Teachers and Teaching: Theory and Practice, 15(2), 273-289. https://doi.org/10.1080/13540600902875340

Haimovitz, K., \& Dweck, C. S. (2017). The origins of children's growth and fixed mindsets: New research and a new proposal. Childhood Development, 88(6), 1849-1859. https://doi.org/10.1111/cdev.12955

Harris, A. (2008). Distributed leadership: According to the evidence. Journal of Educational Administration, 46(2), 172-188. https://doi.org/10.1108/09578230810863253

Harris, J., Carrington, S., \& Ainscow, M. (2017). Promoting equity in schools: Collaboration, inquiry and ethical leadership. London: Routledge. https://doi.org/10.4324/9781315105659

Jordan, W. J. (2010). Defining equity: Multiple perspectives to analyzing the performance of diverse learners. Review of Research in Education, 34(1), 142-178. https://doi.org/10.3102/0091732X09352898

Kaur, B. (2012). Equity and social justice in teaching and teacher education. Teaching and Teacher Education, 28(4), 485-492. https://doi.org/10.1016/j.tate.2012.01.012

Kinloch, V., \& Dixon, K. (2017). Equity and justice for all: The politics of cultivating anti-racist practices in urban teacher education. English Teaching: Practice \& $\quad$ Critique, 16(3), 331-346. https://doi.org/10.1108/ETPC-05-2017-0074

Larrier, Y. I., Hall, K., Linton, J. M., Bakerson, M., Larrier, I. M., \& Shirley, T. S. (2016). Problem based learning: A viable school counseling intervention to promote student engagement with at-risk high school students. National Teacher Education Journal, 9(2), 11-20.

Lee, S. J., \& Walsh, D. (2016). Welcoming immigrant students with a high-quality education. The Phi Delta Kappan, 97(4), 46-50. https://doi.org/10.1177/0031721715619919

Lewis, L., Parsad, B., Carey, N., Bartfai, N., Farris, E., \& Smerdon, B. (1999). Teacher quality: A report on the preparation and qualifications of public school teachers. Statistical analysis report. Washington, DC: National Center for Education Statistics. (ERIC Document Reproduction Service No. ED427009)

Malcom-Piqueux, L., \& Bensimon, E. M. (2017). Taking equity-minded action to close equity gaps. Peer Review, $19(2), 5-8$.

McAllister, G., \& Irvine, J. J. (2000). Cross cultural competency and multicultural teacher education. Review of Educational Research, 70(1), 3-24. https://doi.org/10.3102/00346543070001003

Montgomery, W. (2001). Creating culturally responsive, inclusive classrooms. Teaching Exceptional Children, 33(4), 4-9. https://doi.org/10.1177/004005990103300401

Patterson, J., \& Patterson, J. (2004). Sharing the lead. Educational Leadership, 61(7), 74-78.

Pianta, R., Downer, J., \& Hamre, B. (2016). Quality education in early education classrooms: Definitions, gaps, and systems. The Future of Children, 26(2), 119-137. https://doi.org/10.1353/foc.2016.0015

Rychly, L., \& Graves, E. (2012). Teacher characteristics for culturally responsive pedagogy. Multicultural 
Perspectives, 14(1), 44-49. https://doi.org/10.1080/15210960.2012.646853

Schlanger, P. (2018). Exploring equity issues: Culturally responsive leaders. Bethesda, MD: Center for Education Equity, Mid-Atlantic Equity Consortium.

Severance, S., Penuel, W. R., Sumner, T., Mommandi, W., Quigley, D., Horne, K. V., \& Johnson, R. (2016). Co-designing with teachers for student agency in science. In Researchers and Practitioners Co-Designing for Expansive Science Learning and Educational Equity Symposium. Proceedings. 1128-1135)

Sleeter, C. E. (2012). Confronting the marginalization of culturally responsive pedagogy. Urban Education, 47(3), 562-584. https://doi.org/10.1177/0042085911431472

Taylor, S. E., \& Gollwitzer, P. M. (1995). The effects of mindset on positive illusions. Journal of Personality and Social Psychology, 69(2), 213-226. https://doi.org/10.1037/0022-3514.69.2.213

U.S. Census Bureau. (2018). Classrooms more racially and ethnically diverse. Retrieved from https://www.census.gov/newsroom/press-releases/2018/school-enrollment.html

United States Department of Education (2002). No child left behind act. Retrieved from: https://www2.ed.gov/nclb/landing.jhtml

United States Department of Education (2015). Every student succeeds act. Retrieved from: https://www.ed.gov/essa

Villegas, A. M., \& Lucas, T. (2002). Preparing culturally responsive teachers: Rethinking the curriculum. Journal of Teacher Education, 53(1), 20-32. https://doi.org/10.1177/0022487102053001003

Whitaker, T. (1995). Accomplishing change in schools: The importance of informal teacher leaders. The Clearing House, 68(6), 356-357. https://doi.org/10.1080/00098655.1995.9957270 